\title{
Muscle filaminopathy
}

INSERM

\section{Source}

INSERM. (1999). Orphanet: an online rare disease and orphan drug data base. Muscle filaminopathy. ORPHA:171445

Muscle filaminopathy is a rare myofibrillar myopathy characterized by slowly progressive, proximal skeletal muscle weakness, which is initially more prominent in lower extremities and involves upper extremities with disease progression. Patients present with difficulty climbing stairs, a waddling gait, marked winging of scapula, lower back pain, paresis of limb girdle musculature, hypo-/areflexia and/or mild facial muscle weakness in rare cases. Respiratory muscle weakness is common and cardiac anomalies (conduction blocks, tachycardia, diastolic dysfunction, left ventricular hypertrophy) have been reported in some cases. 